\title{
Reflections on the Respiratory CARe Open Forum
}

Since 1973, the OPEN Forum has been an important feature of the annual congress of the American Association for Respiratory Care. Over the years, many OPEN FoRUM abstracts have led to manuscripts published in RESPIRATORY CARE and in other journals. The first such Open FoRUM abstract was penned in 1975 by former Managing Editor and Editor Emeritus Ray Masferrer. ${ }^{1}$ Since its inception until today, Ray has been instrumental in the evolution of the OPEN Forum.

OPEN ForUm abstracts were first published in print in RESPIRATORY CARE in 1981, a tradition that continued until 2017. Beginning this year, the OPEN FORUM abstracts will not be published in the print Journal but rather online at the Journal's Web site www.rcjournal.com as a supplement to the October issue. Not only is this ecologically sound, but it increases the discoverability of the OPEN FoRUM abstracts online. Persons around the world who conduct an internet search on topics related to Open Forum abstracts will be directed to the Journal's Web site. This will bring increased recognition to the OPEN Forum, the American Association for Respiratory Care Congress, and the respiratory care profession.

The OPEN Forum has become the epicenter for presentation of original research related to respiratory care by respiratory therapists and others. In 2018, 277 abstracts will be presented at the Open Forum in Las Vegas. The OPEN FORUM has become increasingly international. Of the abstracts submitted this year, $15 \%$ were from countries other than the United States: Australia, Brazil, Canada, China, Columbia, Czechia, Hong Kong, India, Italy, Japan, Mexico, Saudi Arabia, Singapore, Taiwan, Thailand, and the United Kingdom. We are indebted to our 39 external reviewers; there were an average of 28 abstracts reviewed by each. Each abstract received an average of 5 reviews. The 2018 Open Forum abstract reviewers are listed at the end of this editorial.

One of us (DH) published an editorial in RESPIRATORY CARE 30 years ago that urged respiratory therapists to con-

Dr Hess has disclosed relationships with Philips Respironics, Ventec Life Systems, Jones and Bartlett, McGraw-Hill, and UpToDate. Mr Branson has disclosed relationships with Aerogen, Bayer, Mallinckrodt, Philips Respironics, and Ventec Life Systems. The remaining authors have disclosed no conflicts of interest.

DOI: $10.4187 /$ respcare. 06567 duct original research on aerosol therapy delivery techniques, to share those research findings at the OPEN FORUM, and to submit manuscripts to ResPiRATORy CARE. ${ }^{2}$ Since publication of that editorial, scores of abstracts on aerosol therapy have been presented at the OPEN ForUm, and many of those studies were eventually published in the Journal. The same can be said for mechanical ventilation and all other aspects of respiratory care. A review of OpEN ForUM abstracts published since 1981 maps the evolution of the respiratory care profession. Indeed, the OPEN Forum provides evidence that we, as a profession, are scientifically curious and that we are invested in establishing the scientific basis for the care that we provide.

The Open Forum has evolved over the years, reflecting a greater emphasis on scientific rigor. Years ago, technical descriptions and protocols, without data, were welcome at the Open Forum. Until recently, case reports were welcome as well. These are no longer considered. Rather, we now consider only original research for presentation. Since 2014, accepted abstracts are presented in 1 of 3 formats: Editors' Choice, Poster Discussions, and Posters Only. Approximately 10 abstracts are chosen for Editors' Choice. Authors of Editors' Choice abstracts present their findings in a brief slide presentation. They must also submit a manuscript to Respiratory CARe. To date, 19 Editors' Choice papers have been published. Poster Discussion sessions are grouped by topic. During the first part of the session, attendees review the posters and discuss them with the authors. In the second part, each author presents a brief oral synopsis of his or her study. Beginning this year, for Posters Only, walk rounds with a facilitator will highlight the important findings. Publication of papers that stem from abstracts from the OPEN ForUm is not limited to the Editors' Choice. All Open Forum presenters are encouraged to submit a manuscript for publication in RESPIRATORY CARE.

In 2004, former Editor-in-Chief David J Pierson published a paper, "How to write an abstract that will be accepted for presentation at a national meeting." ${ }^{3}$ Much of the advice presented by Dr Pierson in that paper remains relevant today. An abstract is limited in the number of words allowed and thus the information communicated is essential to convince the reviewers and editors that the abstract should be accepted for presentation.

The abstract is structured with the headings Background, Methods, Results, and Conclusions. The Background 
should include the aim of the study, the hypothesis, or the research question. The Methods are a concise description of how the research was done. It should identify important aspects of the study, such as clinical versus bench study, retrospective or prospective data collection, and the study population (for a clinical study) or device(s) evaluated (for a bench study). The Results must include data and a statistical analysis of that data. Sometimes this is supplemented with a table or figure, but care should be taken that this will reproduce well. The Conclusion is a brief statement of why the study's findings are important and what they mean. It is important that the Conclusions are supported by the data and does not inflate the importance of the study.

In a 2008 editorial, Pierson ${ }^{4}$ cautions us to be alert for biased and misleading abstracts. These can be difficult to judge during peer review but are something that might be uncovered by OPEN Forum attendees or session moderators. Authors might use the Open Forum to draw attention to a personal agenda or to promote a point of view. Of particular concern is commercial motivation. Although authors are asked to disclose all relationships with industry, biases can be promoted without any financial relationships. This is particularly true for bench studies, in which the methods can be designed to favor one device over another. Even for well-designed bench studies, it is important to appreciate that lung models are not people, and the clinical implications of a bench study should be viewed with some skepticism. Authors of abstracts should, to the extent possible, avoid the use of brand names, particularly in the title of the abstract. The use of brand names creates the perception of an advertisement rather than science.

Another issue that has received attention in recent years is human subjects' protections. Key to this is oversight by an institutional review board (IRB) for any study that involves people. This clearly applies to prospective interventional clinical studies. But, it also applies to retrospective studies, quality improvement studies, and surveys. It applies when the subjects are hospital patients, students, or staff. When considering the study design, the IRB might determine that the study fits one of the exempt categories defined by federal regulations. Although the category is called exempt, this type of research does require IRB review and registration. These studies are not exempt from institutional policies or the requirements for ethical research. It is also important to understand that the IRB, not the investigator, determines whether a study is exempt. Studies with human subjects that have not been considered by an IRB are not acceptable for presentation at the OPEN FoRUM.
The following are common reasons that submitted abstracts are not selected for presentation at the OPEN Forum. We share this to inform authors of future abstracts so that these issues can be avoided:

- An unclear hypothesis or study question.

- Ethical concerns; failure to obtain IRB approval.

- Flawed methodology.

- No data reported.

- No statistical analysis of the data.

- Conclusions not supported by the data.

- Perception of commercial influence.

Together, we have more than 100 years of experience presenting, moderating, and managing the OPEN Forum. This is an endeavor for which we are passionate. Congratulations to each presenter at this year's OPEN Forum. We hope that many of you will accept our invitation to submit your abstract for the 2019 OPEN ForUM. Now is the time to begin.

Dean R Hess PhD RRT FAARC Managing Editor, ResPiratory CARE Irving, Texas

Richard D Branson MSc RRT FAARC Editor-in-Chief, ResPIRATORy CARE Irving, Texas

$$
\begin{array}{r}
\text { Sara Moore } \\
\text { Assistant Editor, RespiRATORy CARE } \\
\text { Irving, Texas }
\end{array}
$$

Ray Masferrer RRT MBA FAARC Editor Emeritus, RESPIRATORY CARE Irving, Texas

\section{REFERENCES}

1. Masferrer R. The Respiratory CARE OPEn Forum. Respir Care 1981; 26(11):1089-1090.

2. Hess D. The Open Forum: Reflections on unanswered questions about aerosol therapy delivery techniques. Respir Care 1988;33(1):19-20.

3. Pierson DJ. How to write an abstract that will be accepted for presentation at a national meeting. Respir Care 2004;49(10):1206-1212.

4. Pierson DJ. Posters and presentations at the Respir CARE Open FoRUM: Valid and objective, or biased and misleading? Respir Care 2008;53(11):1436-1440. 
2018 Open Forum Reviewers

Arzu Ari

Ellen A Becker

Melissa Benton

Peter Betit

Thomas C Blakeman

Robert L Chatburn

John D Davies

Michael D Davis

Kathleen M Deakins

Rajiv Dhand

Robert M DiBlasi

Mohamad El-Khatib

John S Emberger Jr

Kimberly S Firestone

Richard M Ford

Michael A Gentile

Dina Gomaa

Lynda T Goodfellow

Claude Guérin

Jeffrey M Haynes
Carl R Hinkson

Cheryl Hoerr

Robert M Kacmarek

Richard H Kallet

Douglas S Laher

Keith D Lamb

Douglas Masini

Timothy R Myers

Natalie Napolitano

Timothy Op't Holt

Ruben D Restrepo

Dario Rodriquez

J Brady Scott

Craig D Smallwood

Shawna L Strickland

Sarah M Varekojis

Teresa A Volsko

Brian K Walsh

Kimberly S Wiles 